\title{
Mars Surface Systems Common Capabilities and Challenges for Human Missions
}

\author{
Larry Toups \\ NASA Johnson Space Center \\ 2101 NASA Parkway \\ Houston, TX 77058 \\ 281-244-7974 \\ larry.toups-1@nasa.gov
}

\author{
Stephen J. Hoffman \\ Science Applications International \\ Corp. \\ 2450 NASA Parkway \\ Houston, TX 77058 \\ 281-483-9264 \\ stephen.j.hoffman@nasa.gov
}

\begin{abstract}
This paper describes the current status of common systems and operations as they are applied to actual locations on Mars that are representative of Exploration Zones (EZ) NASA's term for candidate locations where humans could land, live and work on the martian surface. Given NASA's current concepts for human missions to Mars, an EZ is a collection of Regions of Interest (ROIs) located within approximately 100 kilometers of a centralized landing site. ROIs are areas that are relevant for scientific investigation and/or development/maturation of capabilities and resources necessary for a sustainable human presence. An EZ also contains a habitation site that will be used by multiple human crews during missions to explore and utilize the ROIs within the $\mathbf{E Z}$.
\end{abstract}

The Evolvable Mars Campaign (EMC), a description of NASA's current approach to these human Mars missions, assumes that a single EZ will be identified within which NASA will establish a substantial and durable surface infrastructure that will be used by multiple human crews. The process of identifying and eventually selecting this single EZ will likely take many years to finalized. Because of this extended EZ selection process it becomes important to evaluate the current suite of surface systems and operations being evaluated for the EMC as they are likely to perform at a variety of proposed EZ locations and for the types of operations - both scientific and development - that are proposed for these candidate EZs. It is also important to evaluate proposed EZs for their suitability to be explored or developed given the range of capabilities and constraints for the types of surface systems and operations being considered within the EMC.

Four locations identified in MEPAG's Human Exploration of Mars Science Analysis Group (HEM-SAG) report are used in this paper as representative of candidate EZs that will emerge from the selection process that NASA has initiated. A field station site plan is developed for each of these four HEM-SAG sites. Because of the difficulty in getting equipment and supplies to the surface of Mars, specific assessments have been conducted to identify those systems and processes that can perform in multiple, sometimes completely unrelated, situations. Examples of common systems that are assessed at all of these sites include: (a) habitation and associated logistics storage systems, (b) a centralized power plant capable of supplying power to a geographically distributed (but within the central habitation zone) set of systems, (c) mobility systems that can be used to off-load and move payloads to specific locations at the central field station location that could also be used to traverse long distances to reach some of the more remote ROIs and (d) robotic systems that can support various activities (such as system set up and maintenance) at the field station that could also be used to explore scientific ROIs and used to support site-specific ISRU production activities.

\section{TABLE OF CONTENTS}

1. INTRODUCTION

2. COMMON SYSTEMS AND OPERATIONS NEEDED FOR MARS SURFACE EXPLORATION 2

3. FIELD STATION APPROACH .....................................3

4. APPLICABILITY TO MEPAG'S HEM-SAG

LOCATIONS ........................................................................5

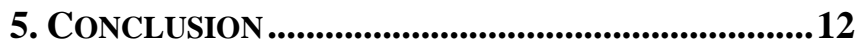

REFERENCES ...........................................................12

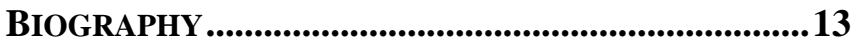

\section{INTRODUCTION}

NASA has begun a process to identify and evaluate candidate locations where humans could land, live and work on the martian surface. These locations are referred to as Exploration Zones (EZs). Given current mission concepts, an EZ is a collection of Regions of Interest (ROIs) that are located within approximately 100 kilometers of a centralized landing site. ROIs are areas that are relevant for scientific investigation and/or development/maturation of capabilities and resources necessary for a sustainable human presence. The EZ also contains a landing site and a habitation zone that will be used by multiple human crews during missions to explore and utilize the ROIs within the EZ.

In parallel with this EZ selection process, NASA continues to make progress on the Evolvable Mars Campaign (EMC), examining alternatives that can pioneer an extended human presence on Mars that is Earth independent. This EMC progress involves ongoing assessments of surface systems and operations to enable a permanent, sustainable human presence. Because of the difficulty in getting equipment and supplies to the surface of Mars, part of these assessments involve identifying those systems and processes that can perform in multiple, sometimes completely unrelated, situations. 
To date these assessments have been performed in a very generic surface mission carried out at a very generic surface location. As specific candidate EZs are identified it becomes important to evaluate the current suite of EMC surface systems and operations as they are likely to perform at specific locations and for the types of operations - both scientific and development - that are proposed for these candidate EZs. It is also important to evaluate the candidate EZs for their suitability to be explored or developed given the range of capabilities and constraints for the types of surface systems and operations being considered within the EMC. This means looking at setting up and operating a field station at a central location within the EZ as well as traversing to and exploring the scientific ROIs within the boundaries of the EZ.

NASA has recently completed the "First Landing Site/Exploration Zone Workshop for Human Missions to the Surface of Mars" at which 47 candidate EZs were presented and discussed [1]. A set of "reference" EZs will eventually be selected from among these proposals to serve as "stressing cases" for the types of analyses necessary to identify those systems and operations best suited for future human missions. Until those "reference" EZs become available the four locations identified MEPAG's Human Exploration of Mars Science Analysis Group (HEM-SAG) [2] will be used as representative of the "reference" EZs.

This paper describes the current status of common systems and operations as they can be applied to actual EZ locations on Mars. The concept of a field station, as currently applied on Earth but now adapted for use on Mars, is described next. This includes a definition of the field station concept and special attributes resulting from its application on the surrogate "reference" EZ locations - those locations identified in the HEM-SAG report. An assessment of lessons learned by applying these concepts and common systems is then discussed to identify a useful approach that can be applied to any proposed EZ, whether it is a designated "reference" location or a proposed specific location with specific attributes and exploration objectives.

\section{COMmon Systems AND OPERATIONS NEEDED FOR MARS SURFACE EXPLORATION}

(Note: This section is in work and will be completed for the final paper.)

Because of the difficulty in getting equipment and supplies to the surface of Mars, specific assessments have been conducted to identify those systems and processes that can perform in multiple, sometimes completely unrelated, situations and locations. Examples of common systems that are assessed at all of the candidate EZ sites include: (a) habitation and associated logistics storage systems, (b) a centralized power plant capable of supplying power to a geographically distributed (but within the central habitation zone) set of systems, (c) mobility systems that can be used to off-load and move payloads to specific locations at the central field station location that could also be used to traverse long distances to reach some of the more remote ROIs and (d) robotic systems that can support various activities (such as system set up and maintenance) at the field station that could also be used to explore scientific ROIs and used to support site-specific ISRU production activities.
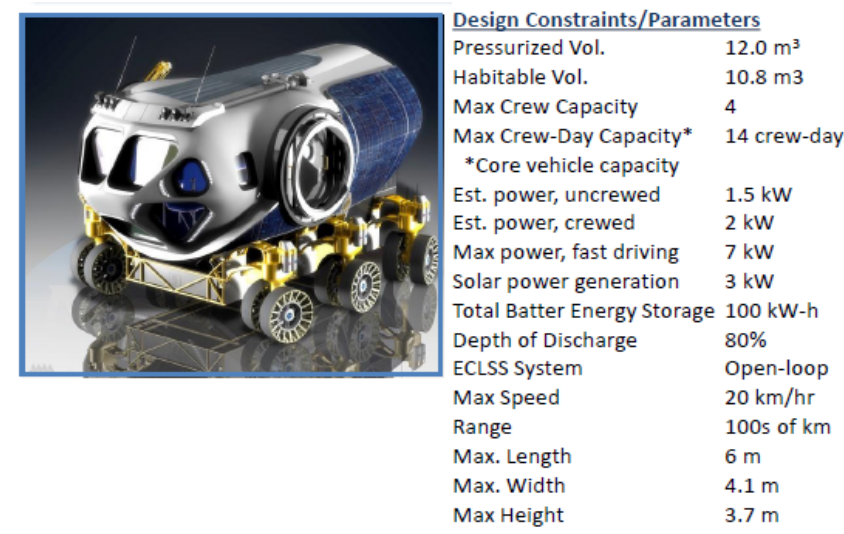

The MSEV is configured as a destination servicing/exploration system for short term mission durations with the capability to support EVAs from the two suitports. The system consists of a core cabin and a destination-appropriate mobility chassis, plus a grappling/docking system. Augmentation modules e.g. a Portable Utility Pallet (PUP) can extend operational durations and ranges.

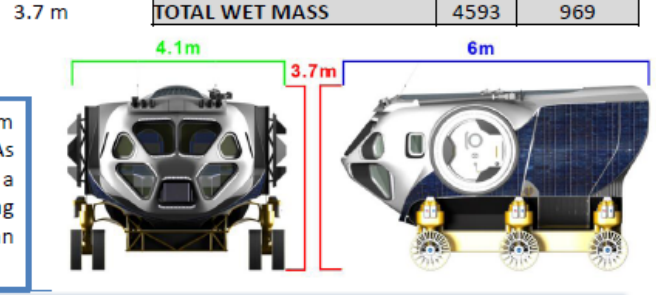

Figure 1 (Caption is TBD)

martian surface. Application of this field station concept and use of common systems is then described at each of the four
Figure 1 illustrates the general capabilities and characteristics of a small pressurized rover concept that 
would fulfill the long-range surface transportation needs of the crew.

Figure 2 illustrates the general capabilities and characteristics of several small rover concepts that would be used in several different situations locally in and around the habitation zone of the EZ and more broadly in exploring the ROIs within the EZ. The Lunar Rover Vehicle (LRV) is representative of a class of simple and short-range rovers capable of carrying EVS crew. The remaining three examples in this Figure are robotic rovers that have been successfully deployed at Mars. There are situations where a specialized version of one of these robotic rovers will be required. For example, a "sterilized" rover that will be used exclusively for investigations of "special regions" where planetary protection concerns apply. However, for other situations it may be possible to accomplish the tasks envisioned for the LRV-like rover with the typically smaller robotic rovers without compromising the overall surface mission but reducing the number and mass of rovers delivered to the surface. identification and analysis of trade studies with NASA's partners and stakeholders. NASA is structuring the EMC such that it can reasonably adjust to changing priorities across the decades.

To guide studies associated with the EMC over the past several years, a set of ground-rules and assumptions were established to examine one particular approach to the human exploration of Mars. Principle among these ground-rules and assumptions that are relevant to activities and results described in this paper was a choice to concentrate all surface assets needed to support human exploration at a single location and then send all crews to this site for subsequent missions in the EMC. This contrasts with the scenario considered in Design Reference Architecture 5.0 (DRA 5.0) [5] in which a campaign of three missions sends crews to three separate stand-alone locations on Mars.

One important facet of these EMC studies is an effort to better understand details of the operations that will be carried out by human crews on Mars and the systems and infrastructure needed to support these operations. These

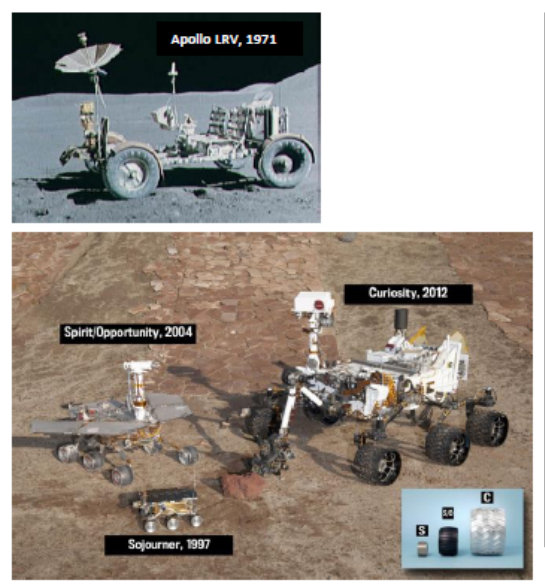

\begin{tabular}{|c|c|c|c|c|}
\hline \multirow[b]{2}{*}{$\begin{array}{l}\text { Design Constraints/ } \\
\text { Parameters }\end{array}$} & \multicolumn{4}{|c|}{ Rover Class } \\
\hline & Apollo LRV & Sojourner & $\begin{array}{c}\text { Spirit/ } \\
\text { Opportunity }\end{array}$ & Curiosity \\
\hline Height (m) & 1.1 & 0.3 & 1.5 & 2.2 \\
\hline Width (m) & 2.3 & 0.5 & 2.3 & 2.7 \\
\hline Length $(\mathrm{m})$ & 3.1 & 0.6 & 1.6 & 3.0 \\
\hline Mass (kg) & 210 & 11.5 & 180 & 899 \\
\hline Max. Velocity $(\mathrm{km} / \mathrm{hr})$ & 18 & 0.02 & 0.18 & 0.14 \\
\hline Range (km) & 92 & 0.5 & $>40$ & $0.2 /$ day \\
\hline Power Source & $\begin{array}{c}2 \text { each } 36 \mathrm{~V} \\
\text { Non- } \\
\text { rechargeable } \\
\text { Batteries }\end{array}$ & $\begin{array}{c}0.22 \mathrm{~m}^{3} \text { Solar } \\
\text { Array + } 9 \text { ea. } \\
\text { D-Cell Size } \\
\text { Batteries }\end{array}$ & $\begin{array}{c}1.3 \mathrm{~m}^{3} \text { Solar } \\
\text { Array + ea. } \\
\text { Batteries }\end{array}$ & \begin{tabular}{|c|} 
Multi- \\
Mission \\
Radioisotope \\
Thermo- \\
electric \\
Generator \\
(MMRTG)
\end{tabular} \\
\hline Peak Power (W) & & 30 & 16 & 110 \\
\hline Battery Capacity & $242 \mathrm{~A}-\mathrm{h}$ & $150 \mathrm{~W}-\mathrm{h}$ & $900 \mathrm{~W}-\mathrm{h}$ & $84 \mathrm{~A}-\mathrm{h}$ \\
\hline Crew Capacity & 2 Crew & $\mathrm{n} / \mathrm{a}$ & $\mathrm{n} / \mathrm{a}$ & TBD \\
\hline
\end{tabular}

Small robotic rovers, such as Sojourner or Spirit/Opportunity-class rovers, could perform duties that human crews can't or aren't available to do, such as: moving surface assets during un-crewed cargo missions; exploring Mars special regions that have not yet been exposed to potential human contaminants; ferrying collected samples from remote sites to the return vehicle. Larger, unpressurized rovers, such as the Apollo-or Curiosity-class rovers, could be used as EVA rescue vehicles or to ferry suited crew members between pressurized modules.

\section{Figure 2 (Caption is TBD)}

\section{FIELD STATION APPROACH}

Over the past several years, NASA has been implementing the NASA Authorization Act of 2010 [3]. The Act calls on NASA to (1) develop and evolve the Space Launch System (SLS) rocket and Orion crew vehicle and (2) to expand human exploration beyond low Earth orbit to cis-lunar space destinations, leading eventually to the international exploration of Mars. To satisfy the second of these actions NASA is defining a long-term, flexible and sustainable deep space exploration architecture termed the "Evolvable Mars Campaign" (EMC) [4]. In short, the EMC provides a basis for (1) overall campaign architecture development, and (2) studies recognized that in addition to scientific questions there would be "known unknowns" associated with exploration of Mars that can only be addressed and understood by human crews living and working on Mars [6]. Several of the more significant "known unknowns" that will need to be addressed include the following:

- Human physiological reaction to the Mars environment (e.g., gravity, radiation, dust, etc.)

- Plant physiological reaction to the Mars environment (e.g., gravity, radiation, lighting, etc.)

- Sources and extraction/processing technology for water

- Martian civil engineering "best practices" (e.g., surface preparation/stabilization) 
- Martian chemical engineering "best practices."

Addressing these questions could require a significant amount of time and effort to attain usable results; possibly spanning the missions of several crews. The EMC has recently adopted a three-phased approach to establishing a single surface site that is capable of addressing these questions as well as equally important scientific questions [6]. Figure 3 illustrates these three phases in the development of this surface site. The "proving ground" phase of this evolution lends itself to a "field station" approach to the development of this central habitation zone / landing site portion of the EZ. In this context, a working definition of a "field station" is as follows [7]:

Field stations create a bridge between natural environments and (Earth-based) research laboratories. Research laboratories offer considerable power to conduct analyses in a predictable environment and to infer cause and effect from manipulative experiments, but they may miss factors that turn out to be critical in a natural environment. Field studies can encompass the full range of relevant interactions and scales, but they are not as tightly controlled. By offering access to both laboratories and field environments, Field Stations combine the best of both worlds.

With this definition in mind the capabilities and constraints of specific surface systems, in particular the systems described in the previous section, must be assessed at specific locations with specific terrain, traverse routes, etc. to develop an optimal field station site plan so that the

\section{APPLiCABILITY TO MEPAG'S HEM-SAG LOCATIONS}

Application of the "field station" concept and use of common systems described in this section as they would be applied at each of the four surrogate "reference" EZ locations - those locations identified in the HEM-SAG report. At the time that this draft was produced these assessments have not yet been completed - the tasks that will produce these results are still in work. This section and the conclusion section will be updated when information from the in-work tasks is available. However, the following items are provided as an indication of the content that will be provided in this section.

The Human Exploration of Mars Science Analysis Group (HEM-SAG) was chartered by the Mars Exploration Program Analysis Group (MEPAG) to develop the scientific goals and objectives for the scientific exploration of Mars by humans. The HEM-SAG was one several parallel NASA humans to Mars scientific, engineering and mission architecture studies going on in 2007 to support NASA's planning for the Vision for Space Exploration (VSE), a plan for space exploration announced in January 2004 by President George W. Bush. The HEM-SAG report was used as input for the Mars Design Reference Architecture 5.0 [5] that was also prepared as an element of the VSE.

The HEM-SAG chose four sites as representative cases of the three major geologic periods in martian history (i.e., Noachian, Hesperian, and Amazonian) and a site that, at that time, was of significant interest for astrobiological research.

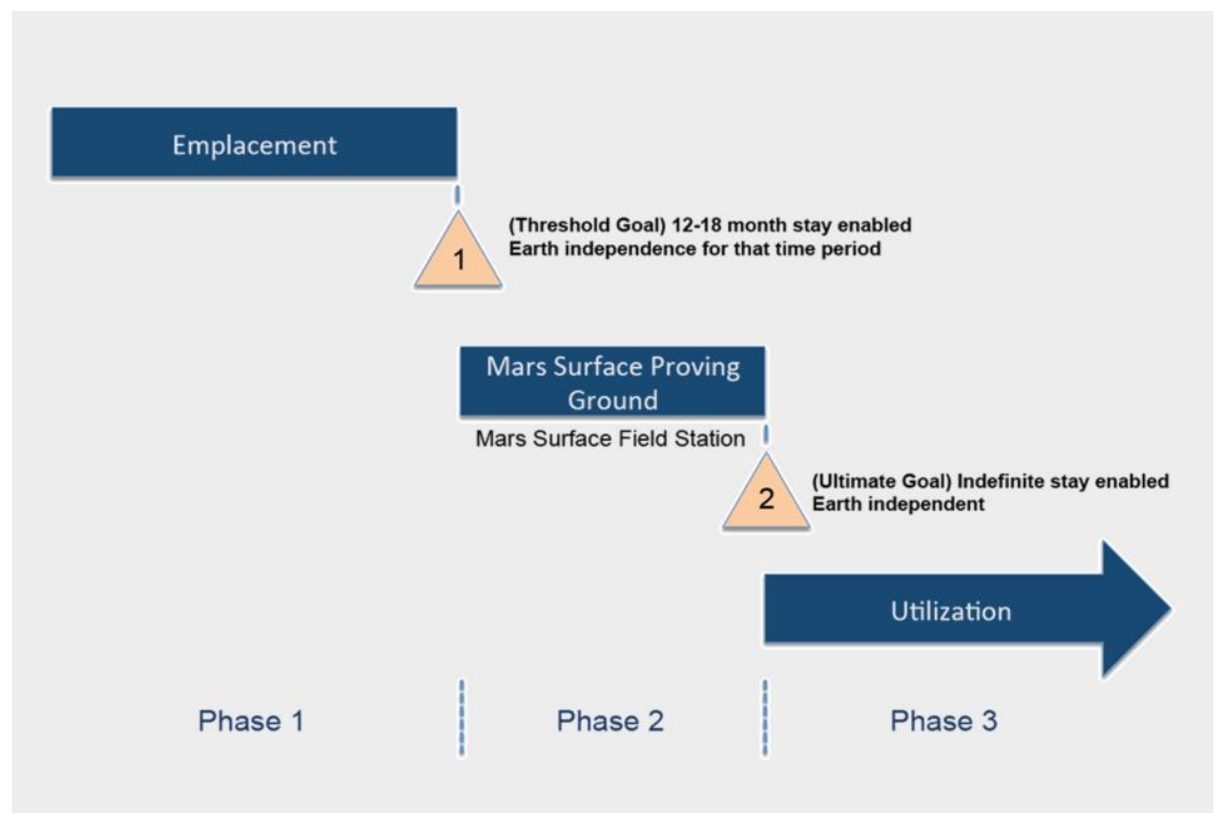

Figure 3 (Caption is TBD)

benefits of this concept can be realized.

The locations of these sites are shown in Figure 4. 


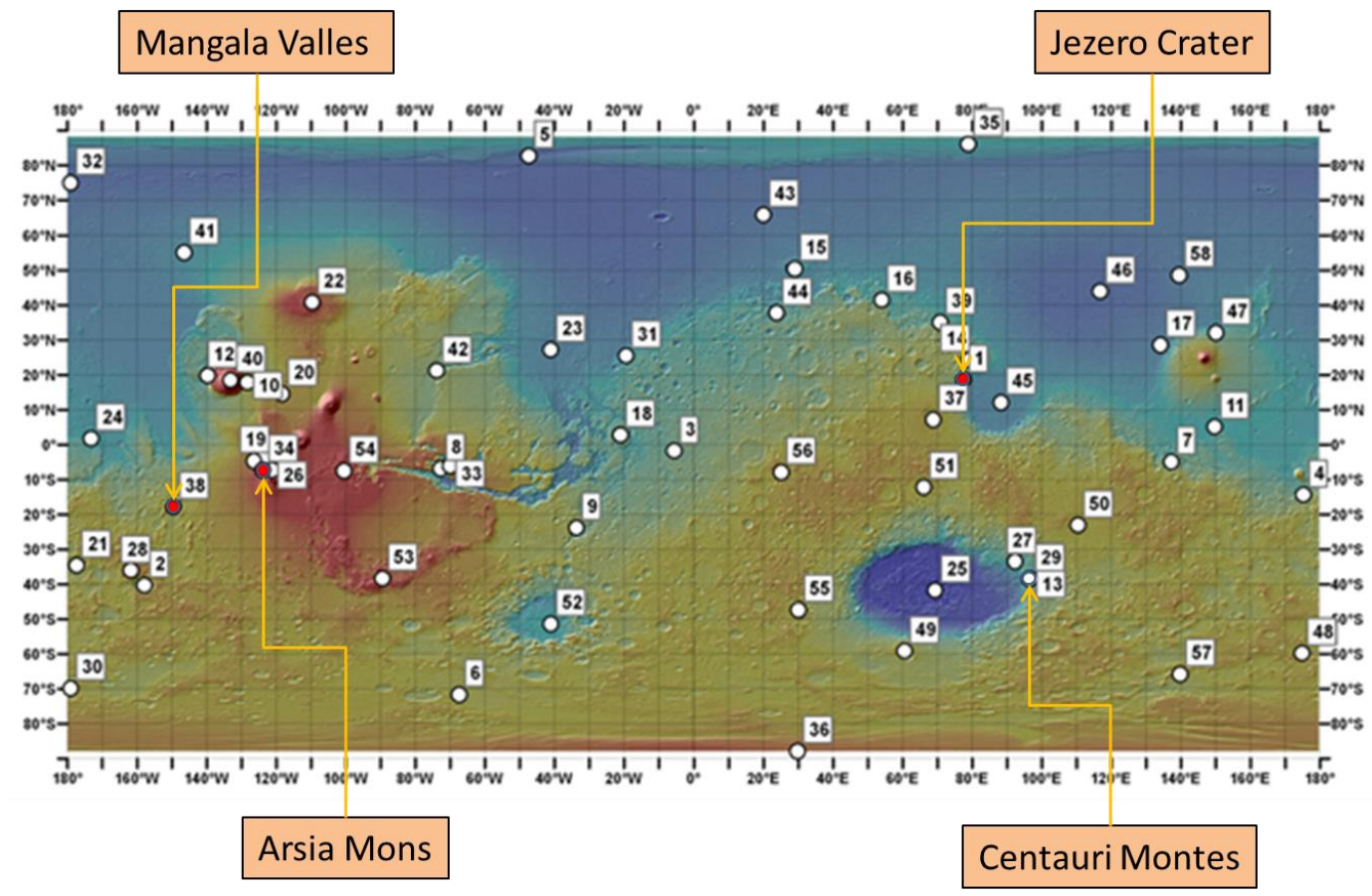

Figure 4 (Caption is TBD)

Application of the previously discussed "field station" concept and use of common systems is described in the following sections.

\section{Jezero Crater}

As described in the HEM-SAG report:

Jezero Crater is a $~ 45$ kilometer diameter impact basin, in the Nili Fossae region of Mars. This crater on the northwest margin of the Isidis impact region is very important for understanding the formation of the Isidis basin, the alteration and erosion of this Noachain (i.e., oldest geologic era) basement, and subsequent volcanism and modification [8] [9]. The crater rim has been breached in three places: twice where channels from the neighboring highlands to the west have drained into the crater from the northwest, and once on the eastern margin where the crater has drained eastward towards the Isidis basin. [10] Each input channel deposited deltas on the crater floor that have been preserved and reveal sedimentary structures and clay deposits in high-resolution images and spectral [11] [12]. Other parts of the crater floor appear to have been resurfaced by lava.

A proposed set of traverses to several ROIs in the vicinity of Jezero are shown in Figure 5.

The distance of each of the proposed traverses in Figure 5 were estimated to determine the ability of robotic rovers and the small pressurized rovers used by the crew to complete a round trip. The horizontal distance travel as well as the elevation gain and loss are shown in Figure 6. An assessment of the capability of these two rover types indicates (note: results to be available after in-work tasks are completed). 


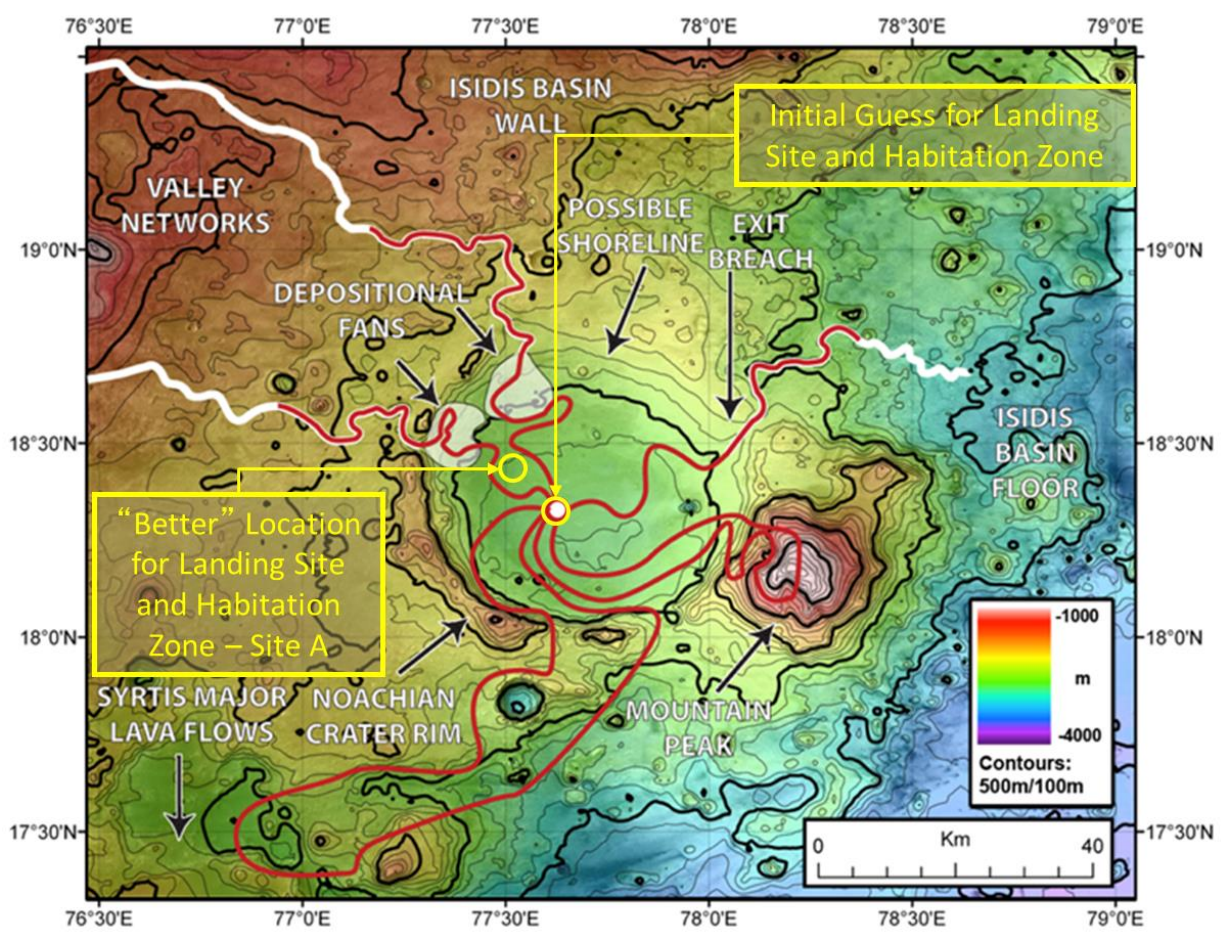

Figure 5 (Caption is TBD)

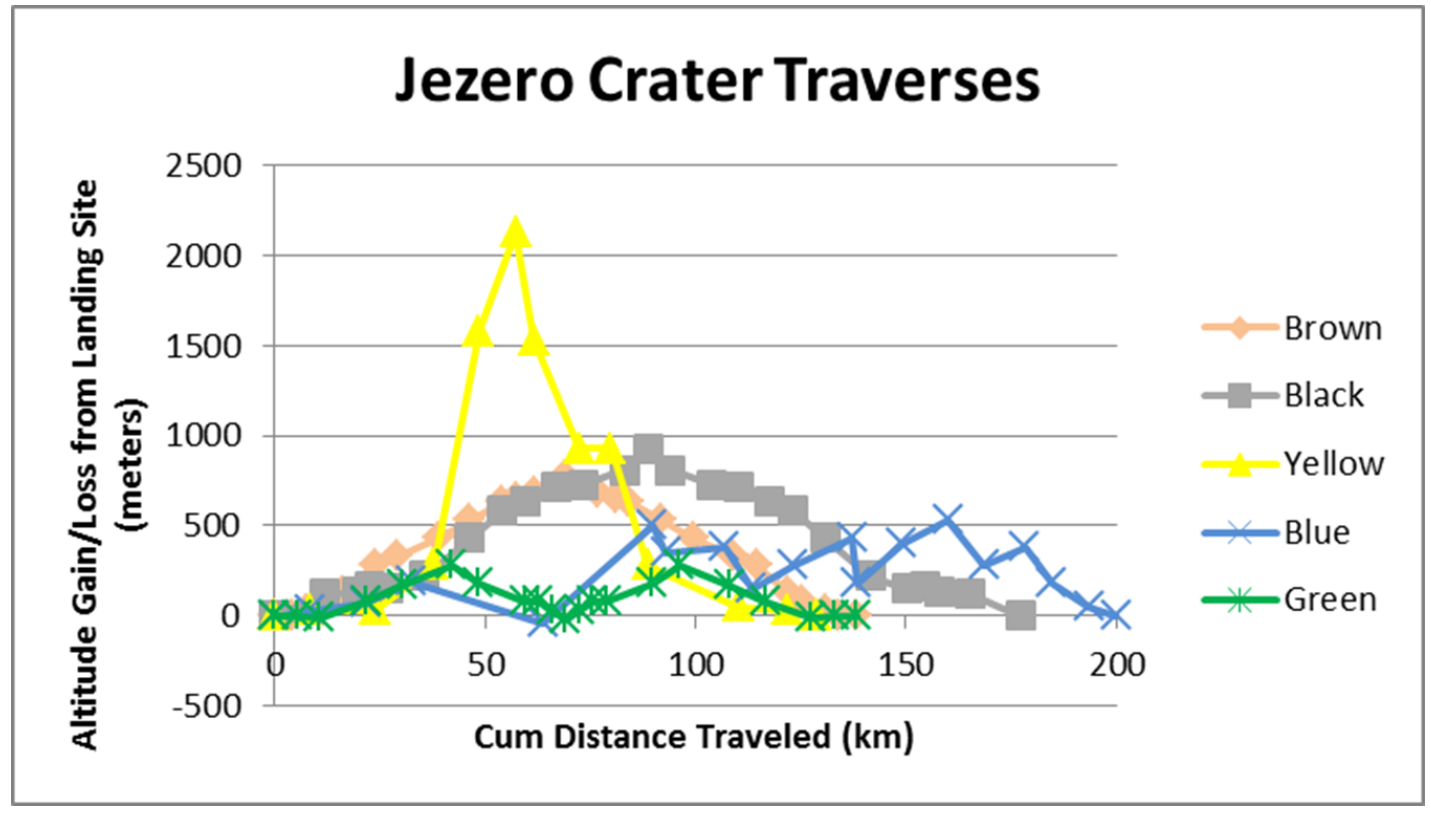

Figure 6 (Caption is TBD)

An examination of HiRISE imagery around the initially proposed landing site indicates that the area was likely unsuitable for repeated landings and use as a habitation zone. However, a suitable location was found in this imagery, resulting in a refined location for the landing site and habitation zone - this is noted as "Site A" in Figure 5.

As part of the process to develop an optimal field station site plan several potential traverses in the local vicinity of the landing site were evaluated and compared to the capabilities of robotic rovers, off-loading equipment, and the small pressurized rovers used by the crew. A representative example illustrating one case of selected landing sites, surface infrastructure sites, and local traverses is shown in Figure 7.

Following several evaluations of this type a final site plan for the Jezero Crater landing site and habitation site was prepared. This is shown in Figure 8. 


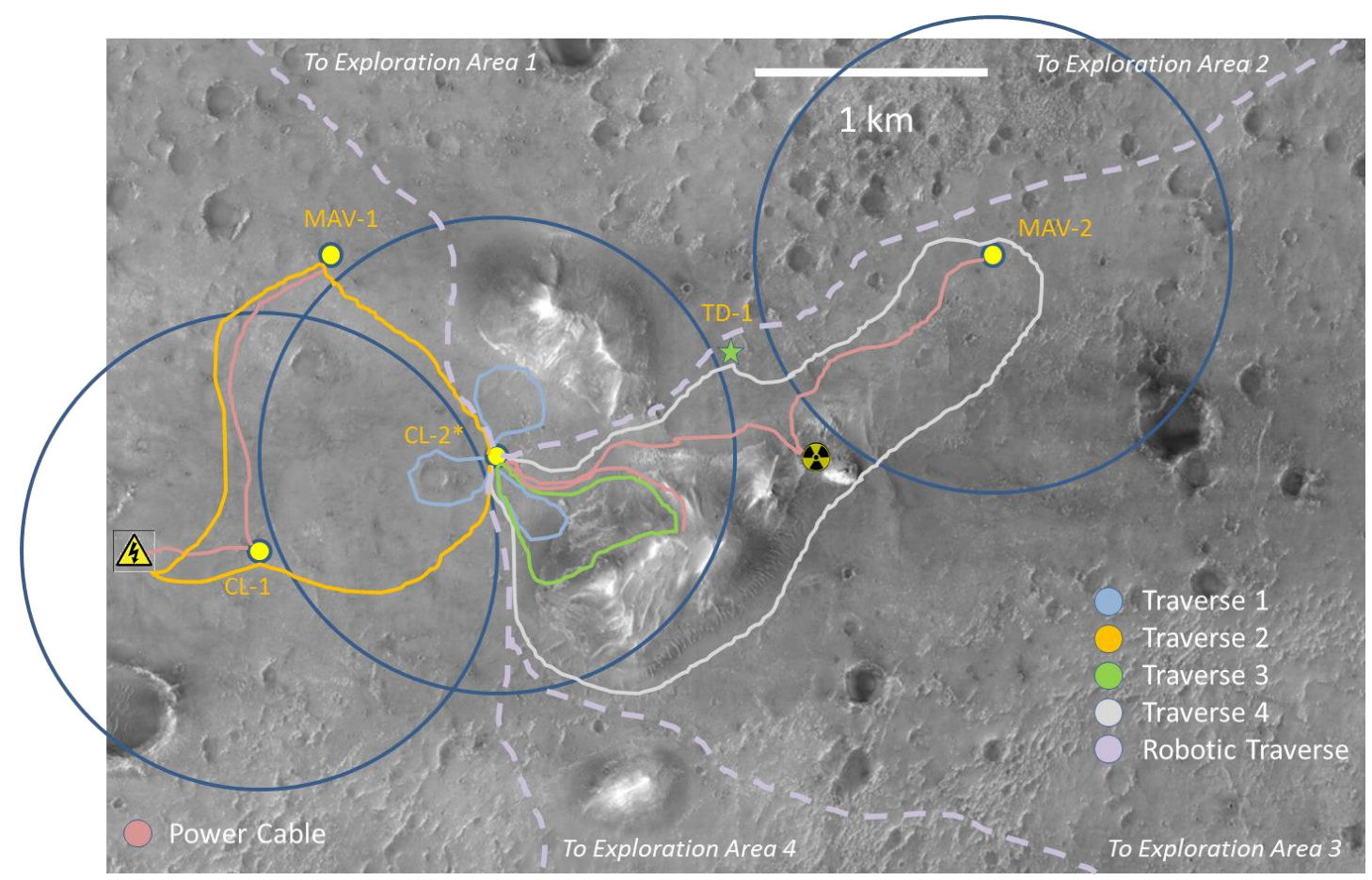

Figure 7 (Caption is TBD)

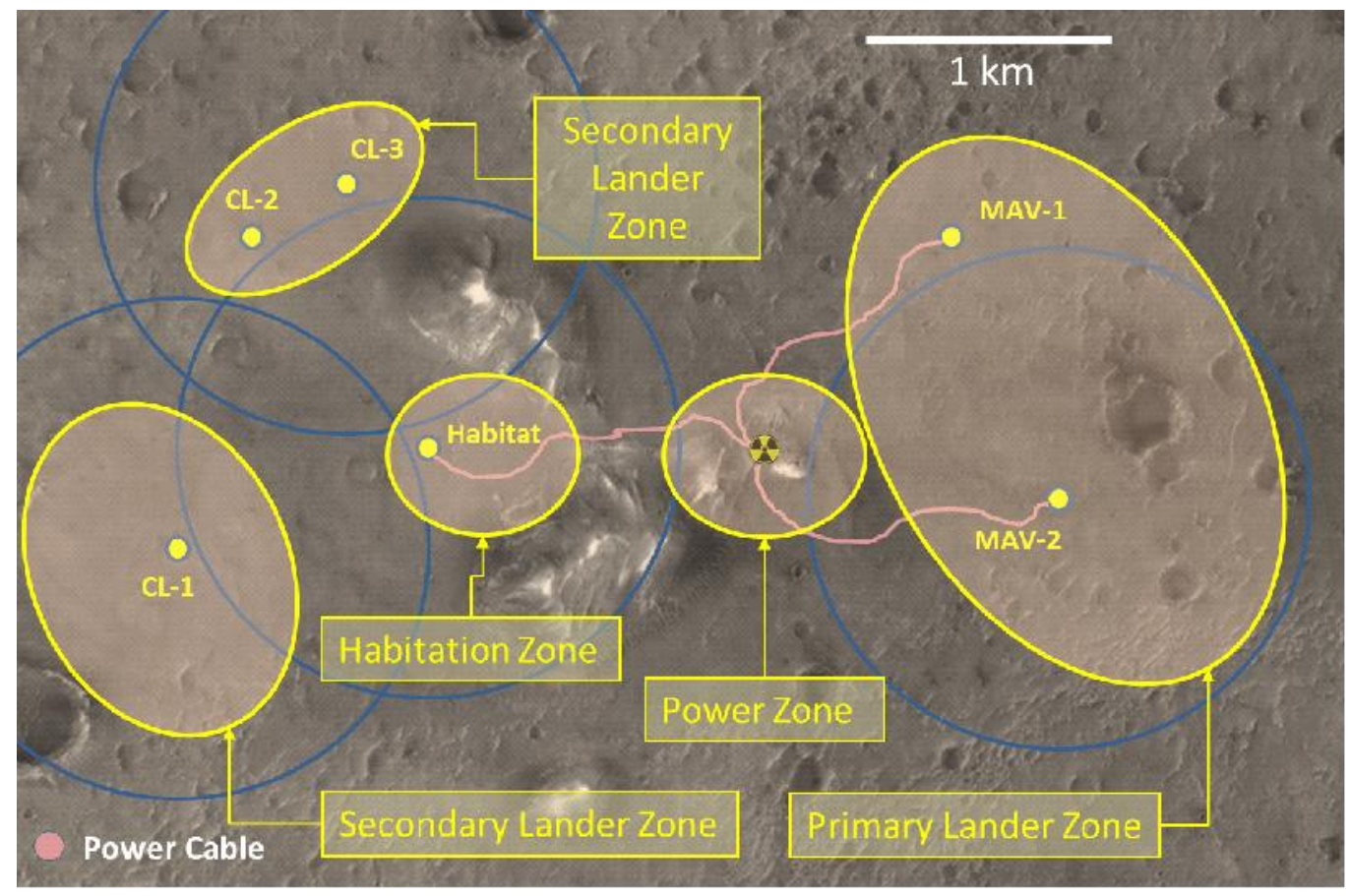

Figure 8 (Caption is TBD)

The area indicated as the "primary lander zone" would be used by MAV vehicles and has space for at least two active MAVs to be located in this area without risk of landercreated debris damage discussed previously (the blue circle is an indication of the potential range of this flying debris). The areas indicated as "secondary landing zones" would be used by cargo-only landers and would be situated closer to the proposed habitation zone, which for this example was chosen to be near the low hills at the center of Site A. A relatively flat area located among the low hills was identified that would make a suitable location for the fission power plant that will supply power for the entire landing site and habitation zone: it is located roughly equidistant from the habitation zone and primary lander zone and the low 
hills surrounding it provide a natural form of radiation protection.

\section{Mangala Valles}

As described in the HEM-SAG report:

Mangala Valles is an Hesperian-aged outflow channel which has received considerable attention on account of its role in global cryosphere/hydrosphere interactions, as well as the possibility that it contains icy near-surface deposits (Levy and Head, 2005; Leask et al., 2007a,b; Hanna and Phillips, 2006; Ghatan et al., 2005; Wilson and Head, 2004; Head et al., 2004; Hanna and Phillips, 2007; Leask et al., 2007). Mangala Valles emanates from a graben that is radial to the Tharsis volcanic complex (Figure 9). Massive release of water from the ground at the graben was accompanied by phreatomagmatic eruptions (Wilson and Head, 2004) and caused catastrophic flow of water to the north, carving streamlined islands. There are also young glacial deposits along the rim of the graben (Head et al., 2004) and evidence for glacial scour having modified the surface of the outflow channel.

This site shows evidence for fluvial, volcanic, tectonic and glacial activity and complicated interactions among them. A landing site in the smooth terrain at the center of the outflow channel would provide access to a variety of sites of interest. Traverses to the channel head and the graben would allow direct observation of cryosphere-breaching geological activity. Traverses along the floor of the outflow channel, as well as on the scoured plains would provide insight into outflow flood hydrology and erosion processes, as well as provide an opportunity for sampling ice-rich deposits which may contain ancient flood residue. A traverse to the vent-rim glacial deposits would provide access to landforms created by volcano-ice interactions, as well as to samples of distal Tharsis volcanic deposits. On the basis of the likelihood that if life exists on Mars, it is most likely to inhabit the subsurface, a site such as Mangala would offer a unique opportunity to sample for evidence of such activity.

A proposed set of traverses to several ROIs in the vicinity of Mangala Valles are shown in Figure 9.

The distance of each of the proposed traverses in Figure 9 were estimated to determine the ability of robotic rovers and the small pressurized rovers used by the crew to complete a round trip. The horizontal distance travel as well as the elevation gain and loss are shown in Figure 10. An assessment of the capability of these two rover types indicates (note: results to be available after in-work tasks are completed).

Detailed assessments of this site are still underway at the time this draft was prepared.

\section{Arsia Mons}

As described in the HEM-SAG report:

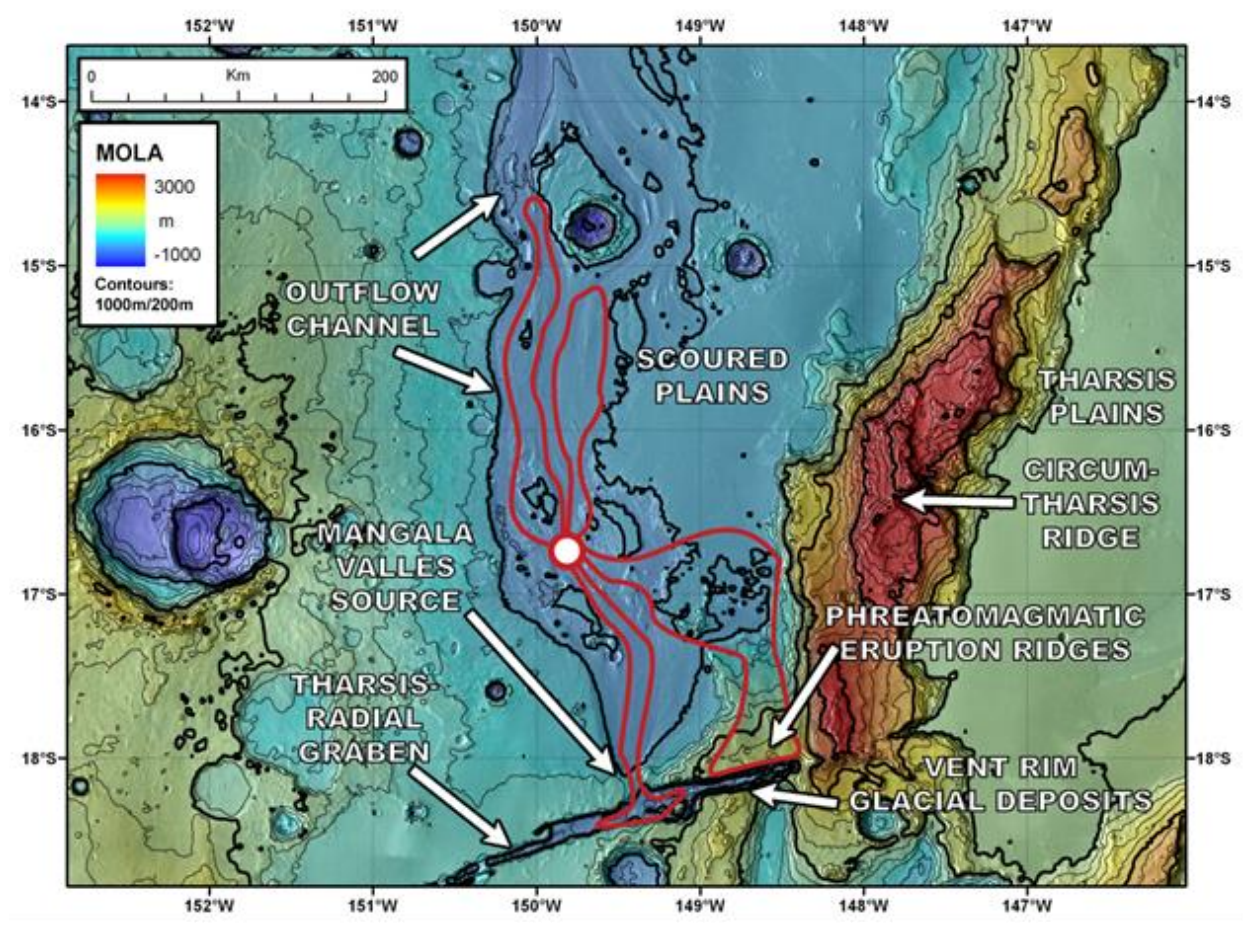

Figure 9 (Caption is TBD) 


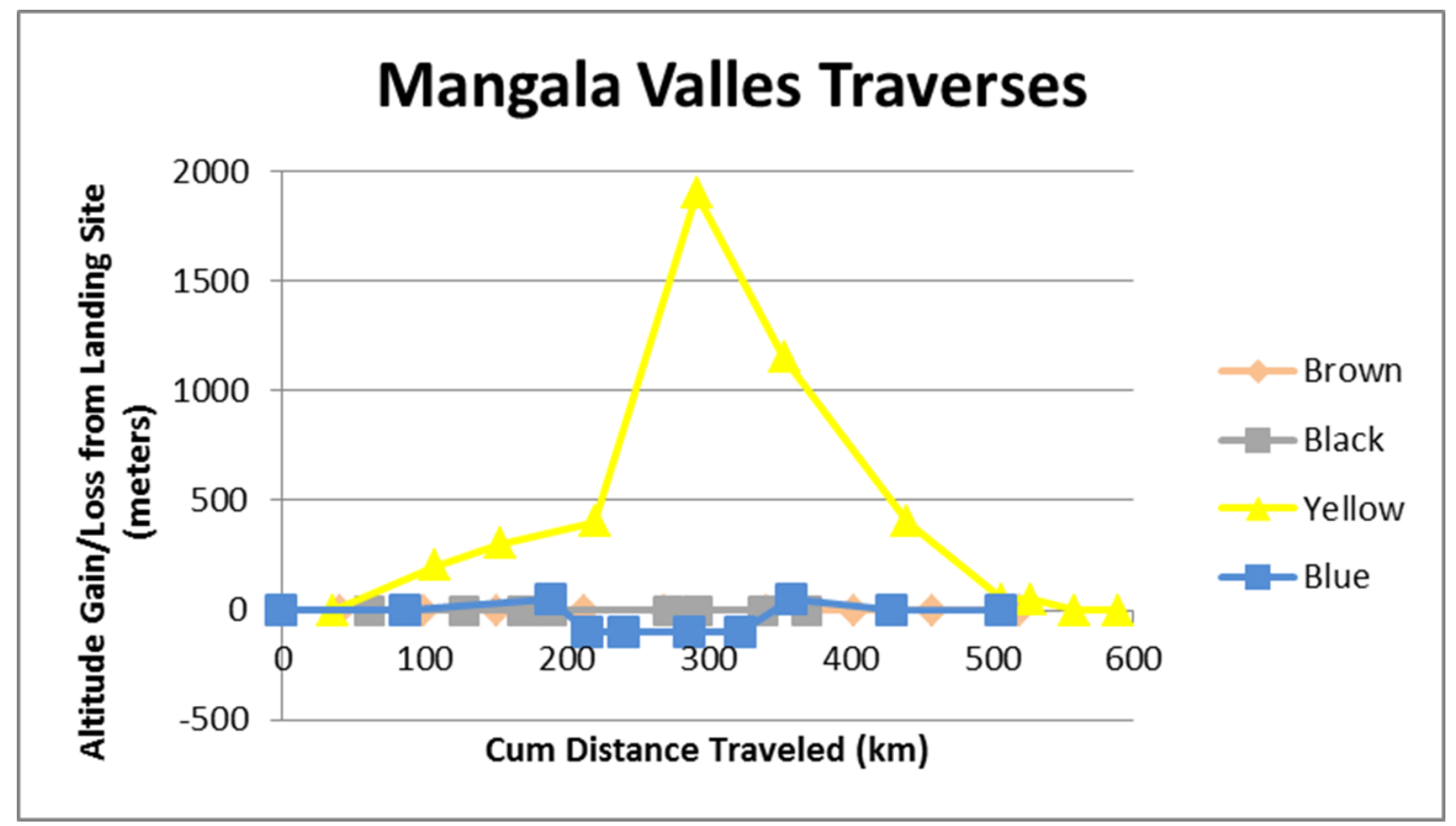

Figure 10 (Caption is TBD)

All three of the major Tharsis Montes shield volcanoes and Olympus Mons exhibit expansive late-Amazonian glacial deposits on their northwestern flanks. The broadest of these deposits are the ones found on Arsia Mons, which show glacial deposits $\sim 400 \mathrm{~km}$ to the west of the accumulation zone and cover an area of about $170,000 \mathrm{~km}^{3}$ (Head and Marchant, 2003). These glacial deposits are found among classic volcanic and tectonic structures, so an extended mission at this location would provide a wealth of information concerning several of the fundamental questions of Martian geology during the Amazonian period.

We designed several traverses from a potential base camp set up at $8^{\circ} \mathrm{S}, 124^{\circ} \mathrm{W}$ (Figure 11) that would analyze the glacial and volcanic deposits, and the complicated relationship between them. Using extended rovers human explorers would be able to ascend the western flank of the shield and systematically obtain targeted samples that elucidate the recent volcanic history of Arsia. Another traverse from the same base camp would provide access to a $\sim 5 \mathrm{~km}$ wide graben that appears to have been a major accumulation zone for much of the observed glacial deposits (Shean et al., 2007). A systematic sampling strategy at this location would provide a history of the flow regime at this site, and drilling at targeted locations could provide the recent climate record for Mars. 
A proposed set of traverses to several ROIs in the vicinity of Arsia Mons are shown in Figure 11.

The distance of each of the proposed traverses in Figure 11 were estimated to determine the ability of robotic rovers and the small pressurized rovers used by the crew to complete a round trip. The horizontal distance travel as well as the elevation gain and loss are shown in Figure 12. An assessment of the capability of these two rover types indicates (note: results to be available after in-work tasks are completed).

Detailed assessments of this site are still underway at the time this draft was prepared.

\section{Centauri Montes}

As described in the HEM-SAG report:

The Centauri Montes site would provide a location for addressing multiple geophysics objectives. First, it is one of three sites for global seismic monitoring. Heat flow measurements for this highlands site could be compared to, for example, such measurements in the large volcanic Tharsis province, if the Arsia site is also chosen.

Figure 13 shows the Centauri Montes site geologic traverse plan with superposed symbols denoting geophysics central station (green square), and satellite stations (red triangles) forming part of the local/regional seismic network and locations of electromagnetic observatories. Exploration targets at this site would include recent gullies (possibly liquid water), ancient Noachian Hellas basin rim constructs, Amazonian debris aprons, and other features associated with geologically recent climate change. The figure shows several traverses, each requiring an extended period of exploration. During these traverses, specific sites would be selected for in-depth geophysical exploration. Active reflection seismology and EM sounding, for example, might be carried out to explore in detail the subsurface structure of these lobate debris aprons.

A proposed set of traverses to several ROIs in the vicinity of Centauri Montes are shown in Figure 13.

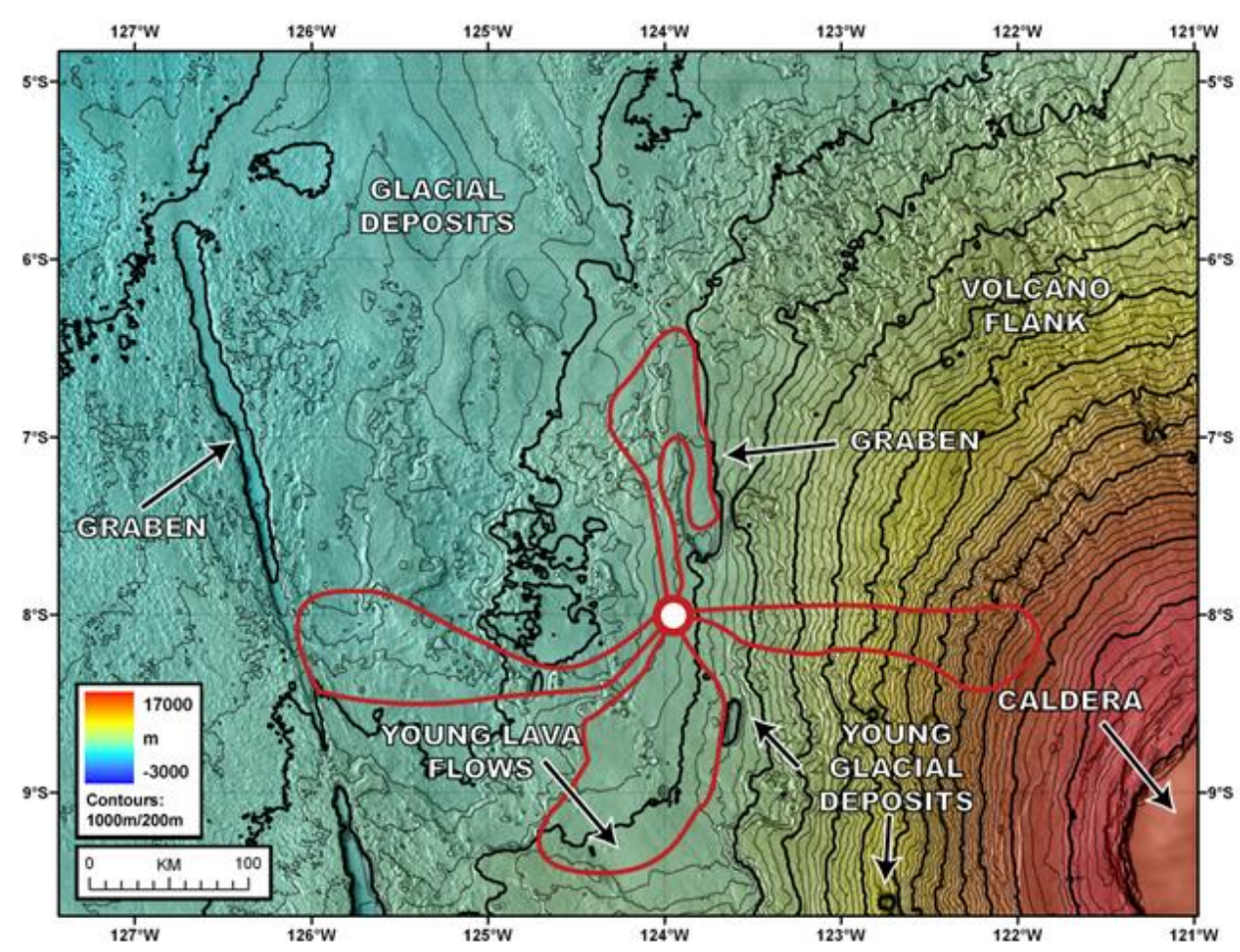

Figure 11 (Caption is TBD) 


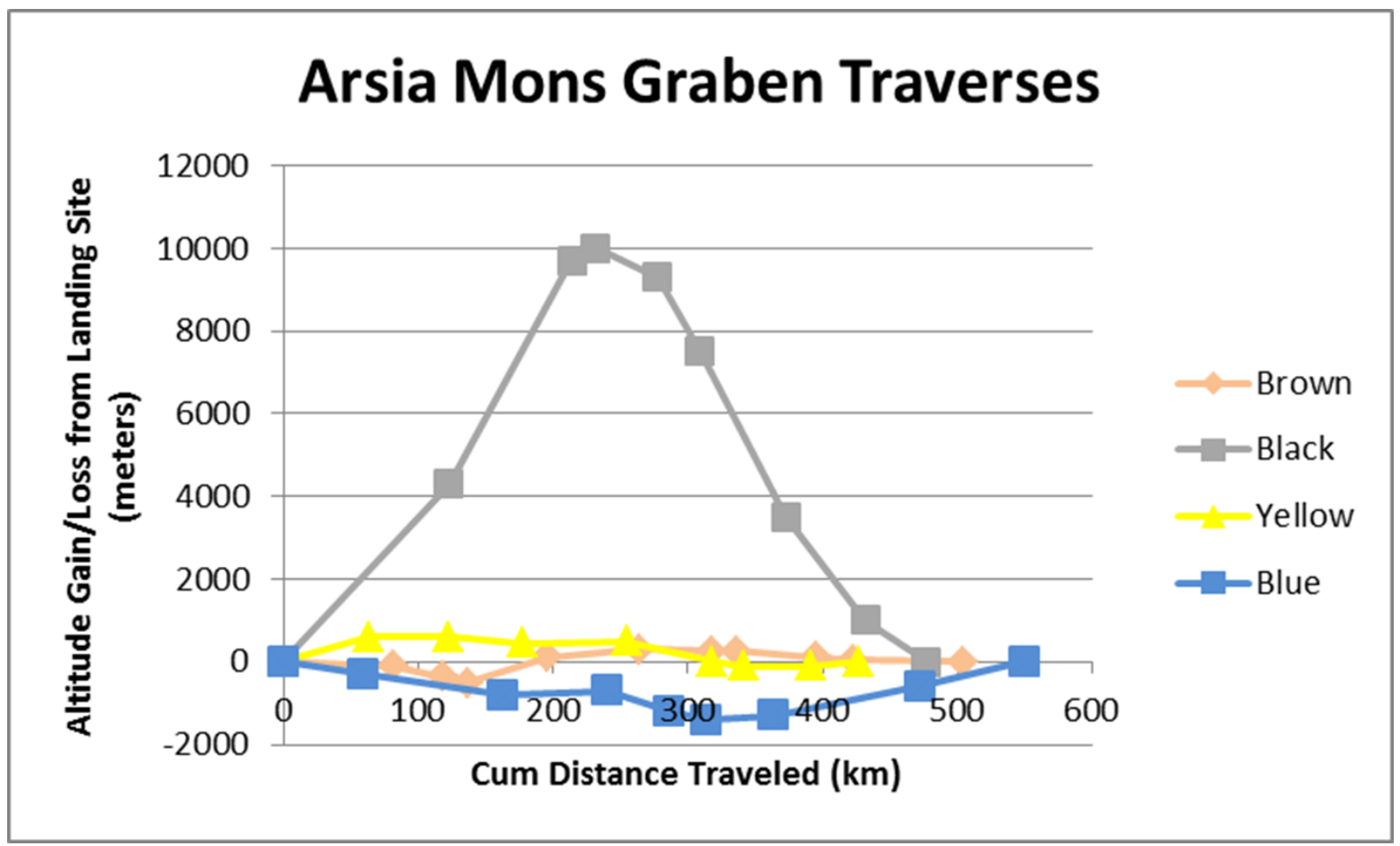

Figure 12 (Caption is TBD)

The distance of each of the proposed traverses in Figure 13 were estimated to determine the ability of robotic rovers and the small pressurized rovers used by the crew to complete a

indicates (note: results to be available after in-work tasks are completed).

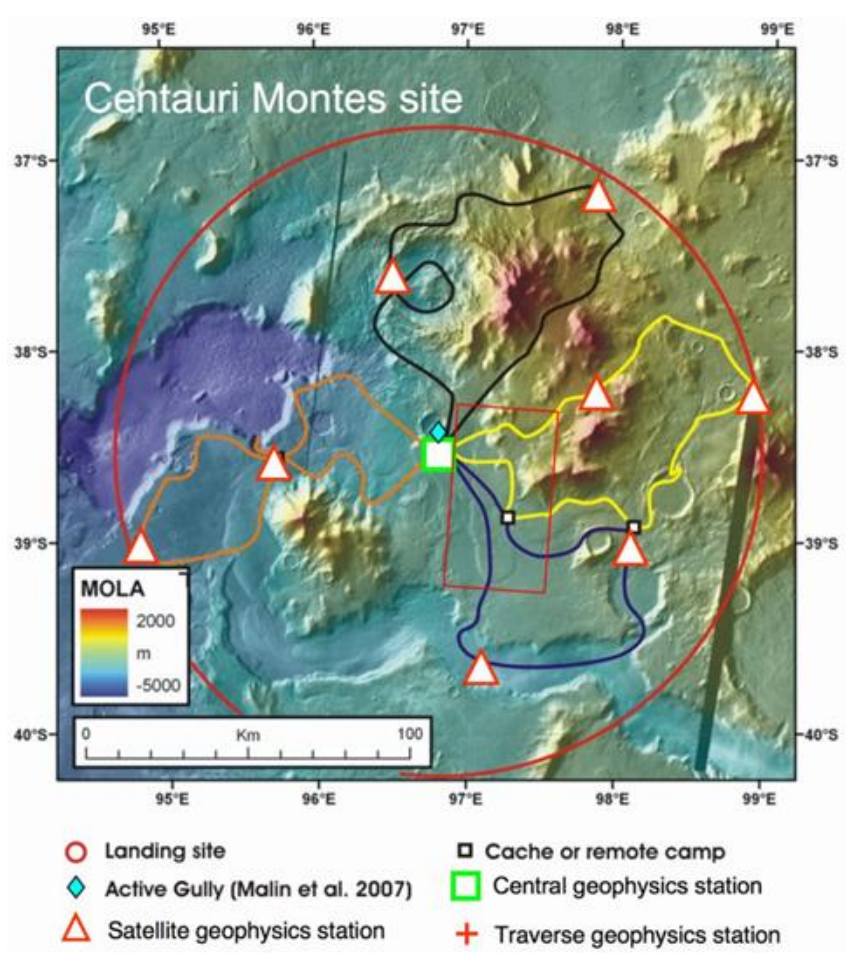

Figure 13 (Caption is TBD)

round trip. The horizontal distance travel as well as the elevation gain and loss are shown in Figure 14. An assessment of the capability of these two rover types
Detailed assessments of this site are still underway at the time this draft was prepared. 


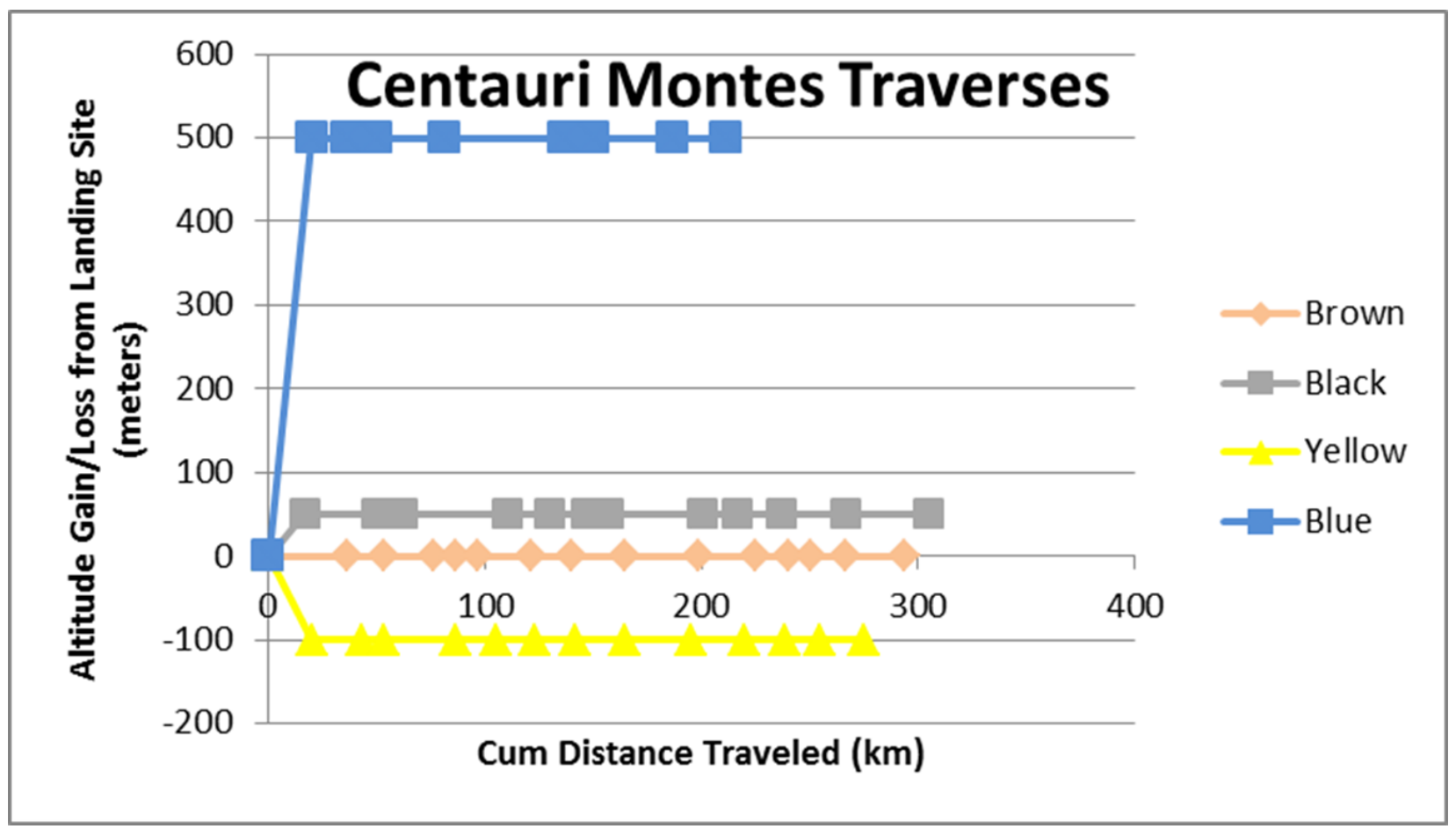

Figure 14 (Caption is TBD)

\section{Conclusion}

A summary of this paper will be presented in this section, including an assessment of lessons learned by applying these concepts and common systems is then discussed to identify a useful approach that can be applied to any proposed EZ, whether it is a designated "reference" location or a proposed specific location with specific attributes and exploration objectives. This section will be updated when information from the currently in-work tasks are available.

\section{REFERENCES}

[1] B. Bussey and S. Hoffman (March 2016). Human Mars Landing Site and Impacts on Mars Surface Operations. IEEE-2016-2515. IEEE Conference. Big Sky, MT.

[2] MEPAG HEM-SAG (2008). Planning for the Scientific Exploration of Mars by Humans, Unpublished white paper, TBD p, posted March 2008 by the Mars Exploration Program Analysis Group (MEPAG) at http://mepag.jpl.nasa.gov/reports/index.html

[3] Citation for NASA Authorization Act of 2010 (in Section 1)

[4] D. Craig; P. Troutman, and N. Herrmann (August 2015). Pioneering Space Through the Evolvable Mars Campaign. AIAA-2015-4409. AIAA Space 2015 Conference. Pasadena, CA

[5] B Drake (2009). Human Exploration of Mars: Design
Reference Architecture 5.0. NASA/SP-2009-566A

[6] L. Toups and S. Hoffman (August 2015). Pioneering Objectives and Activities on the Surface of Mars. AIAA2015-4410. AIAA Space 2015 Conference. Pasadena, CA.

[7] Billick, I., Babb, I., Kloeppel, B., Leong, J.C., J. Hodder, J. Sanders, and H. Swain (2013). "Field Stations and Marine Laboratories of the Future: A Strategic Vision," National Association of Marine Laboratories and Organization of Biological Field Stations [http://www.obfs.org/fsml-future].

[8] Mustard, J. F., F. Poulet, J. W. Head, N. Mangold, J. P. Bibring, S.M. Pelkey, C.I. Fassett, Y. Langevin and G. Neukum, 2007. Mineralogy of the Nili Fossae region with OMEGA/Mars Express data: 1. Ancient impact melt in the Isidis Basin and implications for the transition from the Noachian to Hesperian, J. Geophys. Res., 112, doi: 10.1029/2006JE002834.

[9] Mangold, N., F. Poulet, J.F. Mustard, J. P. Bibring, B. Gondet, Y. Langevinn, V. Ansan, Ph. Masson, C.I. Fassett, J.W. Head, H. Hoffmann and G. Neukum, Mineralogy of the Nili Fossae region with OMEGA/Mars Express data: 2. Aqueous alteration of the crust, J. Geophys. Res., 112, doi: 10.1029/2006JE002835.

[10] Fassett, C. I. and J. W. Head, 2005. Fluvial sedimentary deposits on Mars: Ancient deltas in a crater lake in the Nili Fossae region, Geophys. Res. Lett., 32, doi: 10.1029/2005GL023456. 
[11] Fassett, C. I., B. L. Ehlmann, J.W. Head, J. F. Mustard, S. C. Schon and S. L. Murchie, 2007. Sedimentary fan deposits in Jezero Crater Lake, in the Nili Fossae Region, Mars: Meter-scale layering and phyllosilicate-bearing sediments, AGU Fall Meeting, abstract.

[12] Fassett, C.I., B. L. Ehlmann, J.W. Head, J.F. Mustard, S.C. Schon and S.L. Murchie, 2007. Sedimentary fan deposits in Jezero Crater Lake, in the Nili Fossae Region, Mars: Meter-scale layering and phyllosilicate-bearing sediments, Brown-Vernadsky Micro., 46, abstract.

\section{BIOGRAPHY}

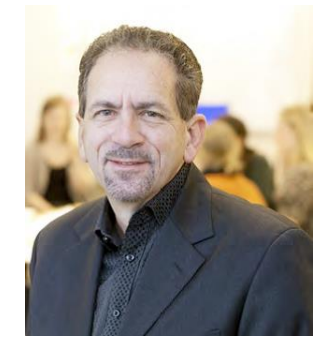

Larry Toups attained a Bachelor of Architecture Degree from the University of Houston. After practicing architecture, he received a Masters Degree in Space Architecture from the University of Houston, Sasakawa Institute for Space Architecture. From June 1988 - January 1994 he was a Senior Engineer with Lockheed Engineering and Sciences Company at Johnson Space Center. In this role, he provided technical support for JSC's New Initiatives Office in the area of Systems Engineering of habitats and planetary systems and contributed to numerous NASA studies. From 1998-2003, Mr. Toups assumed the role of Habitability Systems Lead in the ISS Vehicle Office. He is currently in the Exploration Mission Systems Office at Johnson Space Center.

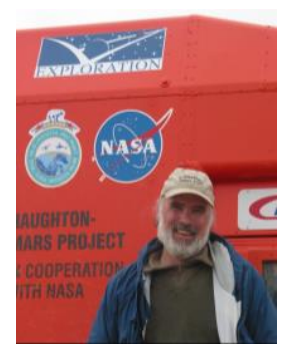

Stephen J. Hoffman received a B.S., M.S., and Ph.D. in Aeronautical and Astronautical Engineering from the University of Illinois in 1978, 1980, and 1984 respectively. Dr. Hoffman is a Senior Systems Engineer with 35 years of experience working in civilian space programs performing tasks involving program management, interplanetary mission planning, preliminary spacecraft design, orbit mechanics, and planetary analog missions. Dr. Hoffman is currently supporting the Exploration Mission Planning Office at the NASA Johnson Space Center. He supports a variety of mission studies and concept assessments associated with human exploration beyond low Earth orbit for this office. 
